\title{
COORDENAÇÃO DE CURSO DE GRADUAÇÃO - DESAFIOS E TENSÕES NA ATUAÇÃO PROFISSIONAL DO PROFESSOR UNIVERSITÁRIO
}

\author{
UNDERGRADUATE COURSE COORDINATION - CHALLENGES \\ AND TENSIONS IN THE PROFESSIONAL PERFORMANCE OF \\ THE UNIVERSITY PROFESSOR
}
COORDINACIÓN DE CURSOS DE GRADUACIÓN - RETOS Y TENSIONES EN EL DESEMPEÑO PROFESIONAL DEL PROFESOR UNIVERSITARIO

Emerson Augusto de Medeiros ${ }^{\mathrm{I}}$ ${ }^{\text {I } U n i v e r s i d a d e ~ F e d e r a l ~ R u r a l ~ d o ~ S e m i-A ́ r i d o ~(U F E R S A), ~ M o s s o r o ́ / R N, ~ B r a s i l ~}$

\begin{abstract}
Resumo Este escrito tem como objeto de estudo a coordenação de curso de graduação. Pretende levantar reflexões acerca de desafios e tensões na atuação profissional do professor universitário no âmbito da coordenação de curso de graduação na Educação Superior. Em termos metodológicos, se configura como um registro teórico-experiencial, uma vez que se ancora na literatura acadêmica, nacional e internacional, acerca da docência universitária e na experiência vivida no contexto da coordenação do Curso de Licenciatura Interdisciplinar em Educação do Campo da Universidade Federal Rural do Semi-Árido (UFERSA), nos anos de 2014 a 2016. Como apontamentos conclusivos, enfatiza que a atuação profissional do professor universitário, na coordenação de curso de graduação, está condicionada à cultura organizacional das instituições universitárias e às relações de poder existentes em cada contexto. Além disso, reforça a necessidade de formação, especialmente na área de gestão universitária, para a atuação na coordenação de curso de graduação, bem como, a demanda de apoio/suporte técnico-administrativo dos departamentos e dos centros acadêmicos, entre outros, no trabalho diário da coordenação. A ausência desse apoio/suporte sobrecarrega o coordenador de curso e precariza sua atuação profissional na Educação Superior.

Palavras-chave: Coordenação de Curso de Graduação; Educação Superior; ProFESSOR Universitário; Licenciatura em EduCaÇão do CAMPo.
\end{abstract}


ABSTRaCr This paper aims to study the coordination of undergraduate course. It intends to raise reflections about challenges and tensions in the professional performance of the university professor within the scope of the coordination of an undergraduate course in Higher Education. In methodological terms, it is configured as a theoretical-experiential record, since it is anchored in academic literature, national and international, on university teaching and the experience lived in the context of the coordination of the Interdisciplinary Rural Education Undergraduate course at the Universidade Federal Rural do Semi-Árido (UFERSA (UFERSA), from 2014 to 2016. As conclusive notes, it emphasizes that the professional performance of the university professor, in coordinating the undergraduate course, is conditioned to the organizational culture of the university institutions and to the existing power relations in each context. In addition, it reinforces the need for training, especially in the university management area, to work in coordinating the undergraduate course, as well as the demand for technical / administrative support from academic departments and centers, among others, in daily work at the coordination. The absence of such support overloads the course coordinator and makes his professional performance in Higher Education more precarious.

Keywords: Undergraduate Course Coordination; College education; College PROFESSOR; RURAL EDUCATION DEGREE.

RESUMEN Este trabajo tiene como objeto de estudio la coordinación de cursos de pregrado. Se pretende plantear reflexiones acerca de desafíos y tensiones en el desempeño profesional del profesor universitario en el ámbito de la coordinación de una carrera de grado en Educación Superior. En términos metodológicos, se configura como un registro teórico-experimental, ya que está anclado en la literatura académica, nacional e internacional, sobre la docencia universitaria y la experiencia vivida en el contexto de la coordinación de la Licenciatura Interdisciplinar en Educación Rural de la Universidade Federal Rural do Semi-Árido (UFERSA), del 2014 al 2016. Como notas concluyentes, se destaca que el desempeño profesional del docente universitario, en la coordinación de la carrera, está condicionado a la cultura organizacional de las instituciones universitarias y a las relaciones de poder existentes en cada contexto. Además, refuerza la necesidad de formación, especialmente en el área de gestión universitaria, para trabajar en la coordinación de la carrera de pregrado, así como la demanda de apoyo técnico / administrativo de los departamentos y centros académicos, entre otros, en el trabajo diario de la coordinación. La ausencia de este apoyo sobrecarga al coordinador del curso y hace más precario su desempeño profesional en la Educación Superior.

Palabras clave: Coordinación de cursos de PRegrado; EduCación universitaria; Profesor universitario; Pregrado en Educación RuRal.

\section{INTRODUÇÃo}

Na literatura nacional e internacional que versa sobre a atuação profissional do professor universitário, temos visto, com muita frequência, o foco de atenção nos processos 
de ensino e de aprendizagem ${ }^{1}$. Isto é, quando nos reportamos para o conjunto de produções científicas que socializam investigações do âmbito da docência universitária e, mais particularmente, da atuação docente na Educação Superior, a preocupação recai, por parte dos investigadores educacionais, para os processos de ensinar e aprender (BARROS; DIAS, 2016; SANTOS, 2016). Questões que envolvem a atuação docente para além das salas de aula não são, nesse sentido, objetos de grande interesse de pesquisa.

Este estudo, seguindo o raciocínio elencado no parágrafo anterior, se constrói a partir de reflexões acerca da atuação profissional do docente universitário no âmbito da coordenação de curso de graduação. Como professor formador no contexto da Educação Superior e tendo exercido a função de coordenador de curso de uma licenciatura por quase dois anos, sentimos a necessidade de aprofundar o debate a respeito do tema. Conforme ressaltado, as pesquisas e as experiências no contexto da coordenação de curso de graduação, entendida neste texto como um espaço de atuação docente para além da sala de aula no Ensino Superior, não são abundantes, evidenciando a demanda para aprofundamentos no âmbito científico e acadêmico.

O presente texto, configurando-se como um registro teórico-experiencial, objetiva refletir acerca de desafios e tensões na atuação profissional do professor universitário na coordenação de curso de graduação na Educação Superior. Para isso, toma como referência central tanto as investigações e produções científicas no âmbito da docência universitária quanto a experiência profissional do autor, exercida na coordenação do Curso de Licenciatura Interdisciplinar em Educação do Campo da Universidade Federal Rural do Semi-Árido (LEDOC/UFERSA), Campus Mossoró, Rio Grande do Norte, Brasil, entre o período de maio de 2014 a março de 2016.

Registramos que, em termos metodológicos, este estudo se entrelaça às produções acadêmicas que exaltam o experienciado/vivido na Educação, ou seja, a experiência será objeto de análise para as reflexões desenvolvidas textualmente, sendo entendida não como algo simples, um acontecimento banal desprovido de reflexividade e de criticidade ao sujeito que o vivenciou. Ao contrário, resgatamos a experiência, pensando sobre ela como o pesquisador espanhol Jorge Larrosa Bondía, o qual a entende a partir de um enfoque interpretativo e crítico-reflexivo "como aquilo que 'nos passa', ou que nos toca, ou que nos acontece, e ao nos passar nos forma e nos transforma” (BONDÍA, 2002, p. 26).

A experiência na coordenação do Curso de Licenciatura Interdisciplinar em Educação do Campo da Universidade Federal Rural do Semi-Árido (LEDOC/UFERSA) deve, na nossa interpretação, ser pensada, problematizada, analisada e refletida, haja vista que o trabalho exercido na condição de coordenador de curso apresentou desafios e tensões que imprimiram importantes questões na nossa atuação profissional na Educação Superior. Entre os desafios e tensões, enfatizamos a relação, algumas vezes difícil, entre o coordenador de curso e as unidades e instâncias acadêmicas (pró-reitorias da instituição; colegiados departamentais), entre outros; a relação entre a dimensão curricular e pedagógica do curso e as demandas advindas dos estudantes oriundos do campo, bem como as questões de cunho metodológico da licenciatura na universidade, entre outras.

1 Na mesma discussão, reforçamos também a ênfase das pesquisas sobre a formação (inicial, continuada e pedagógica) dos professores universitários, conforme apontam Barros e Dias (2016) e Santos (2016). 
Por desafios e tensões, entendemos os obstáculos e as barreiras que emergiram na atuação profissional do coordenador de curso, os quais geraram questionamentos sobre sua função e atribuições profissionais na coordenação, bem como sobrecarga de trabalho físico e mental, precarização de seu exercício docente na Educação Superior e limitações ao seu desenvolvimento profissional no decurso de sua trajetória na coordenação da licenciatura.

Situamos também que o texto se reporta a uma experiência específica vivida na Educação Superior. Ao destacarmos os desafios e as tensões na atuação profissional na coordenação de curso de graduação, nos referimos a um contexto particular: Licenciatura Interdisciplinar em Educação do Campo. Advinda das lutas e reivindicações das populações rurais e dos movimentos sociais do campo, essa modalidade de graduação não se constituiu (ou tem se constituído), no interior das instituições universitárias, de modo tranquilo e com poucos desafios. Os enfrentamentos vivenciados sob diferentes âmbitos pelos professores formadores, estudantes, entre outros profissionais nas universidades, são objetos de estudos em pesquisas da área de Educação (MEDEIROS, 2019; MOLINA; ANTUNES-ROCHA; MARTINS, 2019).

Dessa forma, os escritos que seguem não podem ser tomados em uma perspectiva generalista, a qual se relaciona às demais realidades existentes na Educação Superior. Nos deteremos à experiência da coordenação de curso da Licenciatura Interdisciplinar em Educação do Campo da Universidade Federal Rural do Semi-Árido (LEDOC/UFERSA); licenciatura que, segundo notificamos, se associa à luta histórica das populações rurais e dos movimentos sociais do campo pelo direito à Educação (MUNARIM, 2008; MEDEIROS, 2019). Dito isso, os apontamentos e considerações desenvolvidas ao largo do texto abordarão desafios e tensões que, certamente, não encontraremos (ou encontramos) em outros contextos da Educação Superior, haja vista que as condições políticas, sociais, educacionais e, sobretudo, contextuais são determinantes para a constituição da experiência vivida.

Traçada esta introdução, organizamos o restante do texto em quatro seções: primeiramente, discutiremos sobre a multidimensionalidade da atuação profissional do professor no âmbito da Educação Superior. Em seguida, apresentaremos notas acerca de como se constitui a coordenação de curso de graduação e as atribuições que desenvolve no contexto universitário. Na terceira seção, arrolaremos sobre os desafios e as tensões experienciadas por nós na coordenação de curso na LEDOC/UFERSA, no período de 2014 a 2016. Por último, nas considerações finais, recapitularemos brevemente os principais aspectos destacados nesta produção acadêmica a respeito da atuação profissional do professor universitário na coordenação de curso de graduação.

\section{O PROFESSOR UNIVERSITÁRIO E A MULTIDIMENSIONALIDADE DE SUA ATUAÇÃO PROFISSIONAL}

Se pensarmos, mesmo que rapidamente, sobre o professor universitário e sua atuação profissional no contexto da Educação Superior no Brasil, logo identificaremos, segundo Veiga (2014), que suas atividades profissionais vão muito além do exercício de planejar e ministrar aulas: "lecionar na graduação e na pós-graduação"; "pesquisar"; "orientar trabalhos de conclusão de curso, dissertações e teses"; "supervisionar estágios pós-doutorais"; "orientar 
iniciação científica e monitória na graduação"; "participar de reuniões em comitês e conselhos superiores"; "atuar em bancas avaliadoras"; "produzir/socializar conhecimentos nas esferas acadêmica e científica"; "exercer funções administrativas em pró-reitorias, centros acadêmicos, faculdades, departamentos e coordenações de curso" e "promover extensão" são algumas das atividades exercidas em seu dia a dia pelo docente universitário no Brasil.

Frente aos registros elencados no parágrafo anterior, vemos que sua atuação profissional é multidimensional, agrega diferentes saberes e conhecimentos, sujeitos e práticas. Quando destacamos o caráter multidimensional de seu exercício profissional na Educação Superior, enfatizamos que, de modo diferente do que pensamos, muitas vezes, quando ingressamos no âmbito universitário, sua atuação profissional não se resume ao trabalho em sala de aula e em pesquisa. As atividades administrativas, curriculares, de pesquisa e extensão, para citar algumas, demandam tempo e, pouco a pouco, sobrecarregam o professor. Dada essa realidade, questionamos: o que contribui para tornar multidimensional a atuação profissional do docente universitário no país?

Tardif (2016), em entrevista publicada no ano de 2016 pela Revista Em Aberto, do Instituto Nacional de Estudos e Pesquisas Educacionais Anísio Teixeira - INEP, acerca da docência universitária no Canadá, apresenta considerações relevantes para pensarmos sobre os motivos que contribuíram para que a atuação profissional do docente universitário se tornasse cada vez mais multidimensional. Para o autor canadense, quando olharmos para a atuação profissional do professor universitário, temos que considerar, acima de tudo, a evolução da universidade na história humana e seu papel social.

Segundo Tardif (2016), a universidade em todo o mundo assumiu diferentes papéis em sua história. O autor destaca que, desde o século XIX ao momento atual, há três tendências principais na evolução da universidade, as quais influenciaram diretamente o trabalho do professor universitário, quer a nível local, quer na dimensão macrossocial.

A primeira tendência, conforme notifica o pesquisador, é resultante da profissionalização do trabalho do professor na Educação Superior. Para Tardif (2016), até o início do século XIX, a ciência era comandada pelo amadorismo e boa parte do conhecimento científico se desenvolvia fora das universidades. Com o surgimento do modelo da universidade humboldtiana, em 1809, na cidade de Berlim, Alemanha, o qual se espalhou por todo o ocidente a partir da segunda década do século XX, o docente universitário configurou-se em um pesquisador especializado; da mesma forma, tornou-se um funcionário do Estado (TARDIF, 2016).

A segunda tendência, por sua vez, se refere à democratização da universidade. No século XX, principalmente a partir da década de 1940, ampliou-se o processo de democratização do Ensino Superior no mundo. Com isso, houve um grande aumento no número de universidades, a criação de muitos cursos de graduação, de áreas profissionais e de profissões, resultando no aumento de alunos matriculados na Educação Superior. Tudo isso confluiu para a diversificação do alunado e da própria identidade da universidade (TARDIF, 2016).

A terceira tendência, apontada por Tardif (2016), se situa na instrumentalização das instâncias universitárias a serviço do Estado e da economia. Essa terceira tendência se assenta também na força que o neoliberalismo tem concentrado na área de Educação. Desde a década de 1950 (acentuando-se especialmente na década de 1980), com o crescimento do mercado industrial e a ampliação da Educação Superior pelo mundo, em muitos contextos, 
as universidades "passaram a ser consideradas instrumentos a serviço do desenvolvimento econômico dos Estados-Nação" (TARDIF, 2016, p. 134).

Ora, essas questões influenciaram decisivamente a universidade atual e o trabalho que ela promove, bem como a atuação dos professores que dela fazem parte. No âmbito do ensino universitário, os professores mobilizam um sem-fim de saberes, atuam com um alunado diversificado, muitas vezes de cursos diferentes, necessitando com muita frequência inovar suas ações e práticas docentes (FERREIRA, 2010).

Para Masetto (2015), não faz muito tempo que a atuação profissional do docente no ensino universitário, no contexto da sala de aula, se resumia à aula expositiva. Com a aceleração das mudanças sociais e, principalmente, com o advento expressivo das tecnologias de informação e comunicação na vida social das pessoas e na educação nas últimas décadas, o exercício profissional dos docentes universitários em sala de aula se tornou desafiante e complexo. Para ministrar uma boa aula, o professor universitário necessita tanto de conhecimentos e saberes de natureza diversa (os quais envolvem os conhecimentos e saberes disciplinares da área em que atua, os conhecimentos e saberes pedagógicos e educacionais, entre outros), como de inovação, criatividade, inventividade, estética e afetividade na ação docente (CUNHA, 2016; FRANCO, 2016; WAGNER; CUNHA, 2019).

Veiga (2014), citando Tardif e Lessard (2005, p. 35), ao discutir acerca da diversidade da docência no Ensino Superior, nos apresenta importantes notas sobre a multidimensionalidade da atuação profissional do professor universitário. A autora declara: A docência na Educação Superior é uma ação complexa que requer saberes
específicos, pedagógicos e experienciais. Como ação complexa, a docência é
'um trabalho cujo objeto não é constituído de matéria inerte ou de símbolos,
mas de relações humanas com pessoas capazes de iniciativas e dotadas de
uma certa capacidade de resistir ou de participar da ação dos professores'
(VEIGA, 2014, p. 333).

Além do mais, salvo o trabalho em sala de aula, o docente universitário tem exercido funções na universidade que, até pouco tempo, não lhe consumiam tanto esforço e dedicação. Na pesquisa acadêmica, como fruto dos acordos neoliberais na Educação, o produtivismo se imperou: produzir é o lema, viver ou sobreviver é a questão (ZUIN; BIANCHETTI, 2015; VIANA; MACHADO, 2016). A intensificação nas atividades de pesquisa não comunga com um perfil profissional docente centrado na formação intelectual. A produção científica em larga escala se destaca.

A exigência/cobrança na pós-graduação seleciona, automaticamente, parte dos professores. Os que possuem elevada produção científica sobrevivem, orientam mestrandos e doutorandos, muitas vezes sem recursos e condições materiais para o desenvolvimento das pesquisas (ZUIN; BIANCHETTI, 2015). Em algumas áreas, citamos a Educação, por ser nosso contexto de atuação profissional, esse cenário é avassalador, haja vista que o professor universitário necessita de muito tempo para desenvolver pesquisa, para escrever seus resultados com qualidade e produzir, de fato, conhecimentos científicos que colaborem com o crescimento da ciência e da área. 
No âmbito da extensão universitária, além da participação e organização de eventos científicos, há a intensificação na organização de cursos de formação, tanto na universidade (para os alunos da graduação e da pós-graduação) quanto no contexto externo a ela (para a comunidade social). A orientação de alunos de graduação, na intenção de vinculá-los à extensão, também é reforçada no interior das universidades. A participação em comissões para elaboração de editais internos e externos às instituições merece, neste instante, destaque.

Já no contexto da gestão universitária, são os professores universitários os protagonistas em funções administrativas. Exercem as funções de pró-reitores, de diretores de centros acadêmicos e faculdades, de chefias de departamentos, de coordenadores de cursos de graduação e de pós-graduação, entre outros. Para além dessas funções que estão mais diretamente vinculadas às questões da gestão na universidade, a participação/representação nos conselhos universitários, como os conselhos de ensino, pesquisa e extensão, os conselhos administrativos superiores, os conselhos fiscais, entre outros, deve ser citada. A participação/representação em comitês de ética em pesquisa e em colegiados de cursos também merece atenção nessa discussão, uma vez que apresenta estreita relação com o desenvolvimento das atividades acadêmicas das instituições.

Por tudo que discutimos nesta seção, ressaltamos, mais uma vez, que a atuação profissional do docente na Educação Superior se produz de modo complexo, envolvendo diferentes relações com sujeitos diversos. Assim sendo, defendemos que a atuação do professor universitário tem caráter multidimensional. Está imbricada em inter-relações, as quais são desenvolvidas em processos intersubjetivos e híbridos condicionados por inúmeros fatores internos (como a própria formação docente vivenciada pelo professor que, quase sempre, acontece somente nos diferentes cursos de pós-graduação, evidenciando ausência de formação pedagógica e educacional para a atuação no Ensino Superior) e externos (como as políticas educacionais a nível macrossocial e a cultura organizacional universitária local) a si mesmos.

\section{A Coordenação de Curso de GraduaÇÃo - Como se Constitui e Quais ATRIBUIÇÕES DESENVOLVE NA EDUCAÇÃO SUPERIOR?}

Um dos aspectos que dificultaram a escrita e a produção deste texto é a ausência de materiais/produções científicos que nos ajudassem com reflexões/entendimentos, diretamente, acerca da coordenação de curso de graduação. A literatura educacional, nesse âmbito, é insipiente. Há um vultoso número de produções que discorrem a respeito da gestão educacional de forma ampla, principalmente em relação à gestão de processos educativos escolares na Educação Básica, o que não se evidencia sobre a coordenação de curso de graduação. No entanto, tal característica não foi suficiente para minar nossos esforços de construção do texto.

Iniciamos esta seção destacando importantes questões acerca da coordenação de curso de graduação, objeto de estudo deste texto, as quais serão dialogadas e explanadas na continuidade da seção, a saber: quando a coordenação de curso de graduação foi instituída no contexto da Educação Superior brasileira? O que é a coordenação de curso e qual sua importância para o desenvolvimento do trabalho pedagógico nas graduações? Como as ins- 
tituições de educação superior brasileiras concebem a coordenação de curso de graduação? Quais atribuições desenvolvem nas instituições acadêmicas?

Para responder a essas questões, temos que validar, antes de tudo, uma importante referência: ao falarmos sobre a coordenação de curso de graduação, devemos situá-la tanto no âmbito histórico-político da Educação Superior no país quanto no âmbito local/contextual de cada instituição universitária. A coordenação de curso de graduação se exerce na relação dialética que envolve essas duas dimensões (FERNANDES, 2012). Exercer a função de coordenador de curso em uma instituição de ensino superior privada, no nosso entendimento, não é a mesma coisa que desempenhar tal função em uma instituição pública. Essa intepretação recai também para a modalidade de graduação (presencial, semipresencial ou a distância) e o seu tipo (licenciatura, bacharelado ou tecnológico). Em cada contexto, há uma cultura organizacional/institucional que favorece/limita a atuação da coordenação de curso (ANASTASIOU, 2009; FERNANDES, 2012).

Em referência à primeira questão, declaramos que a instituição da coordenação de curso de graduação tem sua origem na Educação Superior, segundo consta no estudo de doutoramento de Fernandes (2012), na reforma universitária estabelecida pela Lei n. 5.540, de 28 de novembro de 1968. O dispositivo legal introduziu a coordenação de curso como um "órgão" responsável para coordenar e supervisionar as ações pedagógicas e administrativas dos cursos de graduação (FERNANDES, 2012). Complementamos esse apontamento com o que consta no referido documento, quando publicado:

Artigo 13. Na administração superior da universidade, haverá órgãos centrais de supervisão do ensino e da pesquisa, com atribuições deliberativas, dos quais devem participar docentes dos vários setores básicos e de formação profissional.

$\S 1^{\circ}$. A universidade poderá também criar órgãos setoriais, com funções deliberativas e executivas, destinados a coordenar unidades afins para integração de suas atividades.

$\S 2^{\circ}$. A coordenação didática de cada curso ficará a cargo de um colegiado, constituído de representantes das unidades que participem do respectivo ensino (BRASIL, 1968).

Para Fernandes (2012), dada a realidade existente com a instauração do regime militar no período de promulgação da reforma universitária, a coordenação de curso de graduação instituiu-se na Educação Superior inicialmente como um meio de controle e fiscalização dos currículos praticados em cada curso. Posteriormente a esse período e considerando os movimentos educacionais da década de 1980, bem como a promulgação da Lei de Diretrizes e Bases da Educação Nacional - Lei n. 9.394, de 20 de dezembro de 1996, com a ênfase na gestão democrática como o pilar central dos processos administrativos da área de Educação -, houve uma reconfiguração do entendimento sobre a coordenação de curso no interior das instituições universitárias.

Segundo a pesquisadora, no atual contexto nacional podemos compreender a coordenação de curso de graduação como a instância que, no interior de cada instituição de ensino superior, pública ou privada, planeja, organiza, supervisiona e avalia as diferentes atividades dos cursos. Nesse sentido, se refere à instância de gestão dos cursos de graduação 
que impulsionam, conjugam e coordenam o desenvolvimento do conjunto de atividades referentes à implementação dos projetos pedagógicos instituídos nas graduações, ou seja, do(s) currículo(s) oficial(ais) planejado(s) para a formação de estudantes para o exercício profissional em determinada área de conhecimento/profissão (ANASTASIOU, 2009; FERNANDES, 2012).

Vale lembrar que, conforme cada realidade institucional, a coordenação de curso de graduação recebe nomenclaturas variadas (coordenação didática de curso, coordenação pedagógica de graduação, coordenação acadêmica básica, órgão acadêmico básico, colegiado de coordenação didática, entre outros) e assume atribuições diversas que variam entre as atribuições administrativas, pedagógicas, políticas, curriculares e até financeiras (MARCON, 2008; FERNANDES, 2012).

Nesse rol, estando delimitada às prescrições dos estatutos e regimentos universitários, bem como, das diferentes portarias, resoluções, entre outros documentos normativos acadêmicos, a coordenação de curso de graduação é apreendida pelas instituições de educação superior como a instância de referência na gestão e organização do trabalho pedagógico e administrativo dos cursos de graduação (MARCON, 2008; MARCON, 2011). Faz-se importante porque assume o caráter de articuladora na implementação e na construção do(s) currículo(s) dos cursos de graduação. Tem também o caráter político, no sentido de intercambiar as atividades das graduações ao longo dos períodos letivos com a universidade, com seus diferentes sujeitos - professores, estudantes e gestão universitária - e com a comunidade social, em especial com os diversos setores para os quais os cursos de graduação visam formar profissionais.

Esclarecemos que a coordenação de curso de graduação não deve ser concebida como uma instância centralizadora acerca das questões e atividades realizadas nas graduações. Ao contrário, ela se faz com caráter colaborativo, democrático e participativo, uma vez que, para a organização das ações, conta com as deliberações dos colegiados e conselhos de cursos (instâncias formadas pelos professores das graduações), núcleos docentes estruturantes (instâncias que se incumbem de revisar, implementar e acompanhar os Projetos Pedagógicos dos Cursos), entre outros (FERNANDES, 2012).

A partir de um levantamento bibliográfico e documental que realizamos na literatura educacional e normativa brasileira (BRASIL, 1996; BRASIL, 2004; MARCON, 2008; ANASTASIOU, 2009; MARCON, 2011; FERNANDES, 2012), entendemos que as atribuições da coordenação de curso de graduação se materializam na realidade educacional com base em quatro dimensões envoltas à atuação profissional do coordenador, quais sejam: pedagógica; curricular; administrativa e política. Essas atribuições não se corporificam por igual nas práticas profissionais da coordenação de curso de graduação. Em cada contexto, poderá haver a predominância e/ou a acentuação de algumas e a exclusão de outras; porém, entendemos que, de uma forma ou de outra, as dimensões destacadas, as quais agregam o conjunto de atribuições da coordenação de curso de graduação, sempre se fazem existentes. Na sequência (Quadro 1), apresentaremos as dimensões da atuação profissional do coordenador e as atribuições da coordenação de curso de graduação na Educação Superior: 
Quadro 1: Dimensões da atuação profissional do coordenador e atribuições da coordenação de curso de graduação

\begin{tabular}{|c|c|c|c|}
\hline \multicolumn{4}{|c|}{ Dimensões da Atuação Profissional do Coordenador } \\
\hline Pedagógica & Curricular & Administrativa & Política \\
\hline \multicolumn{4}{|c|}{ Atribuições da Coordenação de Curso de Graduação } \\
\hline $\begin{array}{l}\text { - Orientar os estudantes } \\
\text { acerca de aspectos } \\
\text { pedagógicos, didáticos e } \\
\text { curriculares, tais como os } \\
\text { demais aspectos referentes } \\
\text { ao curso (trancamento } \\
\text { de disciplina e do curso; } \\
\text { solicitação de abertura de } \\
\text { turmas especiais, entre } \\
\text { outros); } \\
\text { - Acompanhar os alunos } \\
\text { no período de matrícula } \\
\text { referente a cada semestre } \\
\text { letivo; } \\
\text { - Planejar as atividades do } \\
\text { curso com os professores no } \\
\text { início dos semestres letivos; } \\
\text { - Reunir os professores que } \\
\text { lecionam no curso e discutir } \\
\text { sempre que necessário } \\
\text { sobre as demandas de } \\
\text { ensino e aprendizagem do } \\
\text { alunado, visando assegurar } \\
\text { a qualidade da formação } \\
\text { profissional dos estudantes; } \\
\text { - Atentar para fragilidades } \\
\text { pedagógicas, didáticas e } \\
\text { curriculares do curso e } \\
\text { buscar meios de equacioná- } \\
\text { las; } \\
\text { - Promover a avaliação } \\
\text { contínua do curso, por meio } \\
\text { dos discentes e docentes, } \\
\text { bem como socializá-la } \\
\text { na intenção de refletirem } \\
\text { sobre os processos de } \\
\text { ensino e aprendizagem } \\
\text { desenvolvidos. } \\
\end{array}$ & $\begin{array}{l}\text { - Cuidar da revisão, } \\
\text { implementação e } \\
\text { avaliação do Projeto } \\
\text { Pedagógico de Curso; } \\
\text { - Organizar a oferta } \\
\text { de disciplinas e turmas } \\
\text { referentes a cada semestre } \\
\text { letivo; } \\
\text { - Orientar os professores } \\
\text { acerca da implementação } \\
\text { de questões pedagógicas, } \\
\text { didáticas e, sobretudo, } \\
\text { curriculares referentes ao } \\
\text { curso; } \\
\text { - Contribuir para a } \\
\text { implementação de } \\
\text { políticas internas e } \\
\text { externas à universidade } \\
\text { quanto à pesquisa e à } \\
\text { extensão universitária; } \\
\text { - Preservar a atualização } \\
\text { dos Programas de Ensino } \\
\text { das Disciplinas e dados } \\
\text { do currículo do curso; } \\
\text { - Coordenar os processos } \\
\text { curriculares para a } \\
\text { avaliação do curso junto } \\
\text { ao Sistema Nacional de } \\
\text { Avaliação da Educação } \\
\text { Superior - SINAES; } \\
\text { - Encaminhar ao } \\
\text { colegiado de curso e } \\
\text { instâncias acadêmicas da } \\
\text { universidade providências } \\
\text { para equalizar fragilidades } \\
\text { e necessidades } \\
\text { pedagógicas, didáticas e, } \\
\text { sobretudo, curriculares do } \\
\text { curso. }\end{array}$ & $\begin{array}{l}\text { - Presidir e/ou gerenciar as } \\
\text { reuniões do colegiado de } \\
\text { curso e do núcleo docente } \\
\text { estruturante; } \\
\text { - Zelar pela } \\
\text { implementação no } \\
\text { curso das disposições } \\
\text { normativas e acadêmicas } \\
\text { da universidade, bem } \\
\text { como pelo cumprimento } \\
\text { das decisões do colegiado } \\
\text { de curso, do conselho de } \\
\text { curso e do núcleo docente } \\
\text { estruturante; } \\
\text { - Manter atualizadas as } \\
\text { informações disponíveis } \\
\text { em sites institucionais } \\
\text { acerca do curso; } \\
\text { - Direcionar processos, } \\
\text { pareceres e demandas do } \\
\text { curso para decisões nos } \\
\text { conselhos e colegiados } \\
\text { de curso, bem como } \\
\text { deliberações, quando } \\
\text { necessárias; } \\
\text { - Elaborar calendários } \\
\text { semestrais de reuniões } \\
\text { do colegiado de curso } \\
\text { e do núcleo docente } \\
\text { estruturante, seguindo } \\
\text { as recomendações } \\
\text { estatuárias e regimentais da } \\
\text { instituição; } \\
\text { - Emitir pareceres, sempre } \\
\text { que solicitado pelas } \\
\text { instâncias acadêmicas, } \\
\text { acerca das questões } \\
\text { curriculares e pedagógicas } \\
\text { do curso. }\end{array}$ & $\begin{array}{l}\text { - Representar o } \\
\text { curso nas instâncias } \\
\text { e unidades } \\
\text { acadêmicas da } \\
\text { universidade e fora } \\
\text { dela; } \\
\text { - Dialogar com } \\
\text { a comunidade } \\
\text { social, em especial } \\
\text { com setores e } \\
\text { instâncias do } \\
\text { campo profissional } \\
\text { para o qual se } \\
\text { pretende formar } \\
\text { profissionais; } \\
\text { - Preservar } \\
\text { ações coletivas } \\
\text { e organizadas } \\
\text { do/no curso, } \\
\text { com ênfase no } \\
\text { desenvolvimento } \\
\text { social e } \\
\text { educacional e na } \\
\text { gestão democrática } \\
\text { e participativa; } \\
\text { - Dialogar com } \\
\text { os estudantes do } \\
\text { curso e/ou suas } \\
\text { representações } \\
\text { estudantis sobre } \\
\text { dificuldades } \\
\text { referentes à } \\
\text { permanência na } \\
\text { universidade, } \\
\text { ao ensino e } \\
\text { aprendizagem, } \\
\text { objetivando saná- } \\
\text { las. }\end{array}$ \\
\hline
\end{tabular}

Fonte: Elaborado pelo autor com base em um levantamento bibliográfico e documental, 2020.

Em síntese às considerações destacadas nesta seção, até então, reforçamos que a coordenação de curso de graduação é uma instância central para o desenvolvimento do trabalho pedagógico das/nas graduações. Todavia, tendo como referência nossa experiência profissional, alertamos que muitos obstáculos emergem, rotineiramente, no trabalho promovido por ela. 
Esses obstáculos se referem, em maior proporção, às questões estruturais das instituições (ausência de recursos materiais para o desenvolvimento das atividades do curso, reduzido apoio técnico-administrativo nas atividades, sobrecarga de atribuições à coordenação, pouco tempo para o atendimento das demandas institucionais, entre outros) e relacionais (difícil relação com representantes e gestores de setores acadêmicos da universidade pró-reitores, diretores de superintendências, chefes de departamentos acadêmicos, entre outros). O coordenador de curso, nesse contexto, tem papel central. Ele se insere, quando tem condições profissionais para fazê-lo, como um agente que medeia, gerencia e equaliza as relações e muito dos obstáculos que emergem no cotidiano da coordenação de curso.

\section{A coordenação de Curso da Licenciatura em EducaÇão do Campo - DESAFIOS E TENSÕES DA/NA PRÁTICA PROFISSIONAL}

A Licenciatura Interdisciplinar em Educação do Campo da Universidade Federal Rural do Semi-Árido (LEDOC/UFERSA) teve suas atividades formativas iniciadas no segundo semestre letivo do ano de 2013. É um curso regular de graduação lotado no Departamento de Ciências Humanas, do Centro de Ciências Sociais Aplicadas e Humanas da UFERSA, Mossoró, Rio Grande do Norte, Brasil. Defende como objetivo principal a formação de professores sustentada em três perspectivas: formação para atuação docente nos anos finais do Ensino Fundamental e no Ensino Médio, nas áreas de Ciências Humanas e Sociais e Ciências da Natureza; formação para atuação docente na gestão de processos educativos escolares na Educação Básica; e formação para atuação docente na gestão de processos educativos comunitários no meio rural. Em síntese, tenciona-se com a referida licenciatura a qualificação docente para o exercício profissional em diferentes contextos no/ do campo da mesorregião do oeste potiguar do Estado do Rio Grande do Norte (UNIVERSIDADE FEDERAL RURAL DO SEMI-ÁRIDO, 2013).

No que toca ao seu corpo docente, este é composto por profissionais com formação inicial em variadas áreas do conhecimento, consolidando-se como multidisciplinar: 4 pedagogos; 2 licenciados e 1 bacharel em Ciências Sociais/Sociologia; 1 licenciado em Letras Língua Portuguesa; 1 licenciado em Letras Libras; 1 licenciado em Física; 2 licenciados em Química; 1 licenciado em Ciências (com habilitação em Biologia); 1 licenciado em História; 1 licenciado em Geografia; 1 bacharel em Serviço Social; 1 licenciado em Filosofia e 1 bacharel em Medicina Veterinária e licenciado em Biologia. ${ }^{2}$

Seu alunado, em maioria, é constituído por sujeitos residentes em áreas de assentamento da reforma agrária, por filhos de pequenos agricultores e pecuaristas de cidades interioranas do Rio Grande do Norte e de Estados fronteiriços (Paraíba e Ceará), por professores e profissionais da Educação Básica que atuam no meio rural, por representantes e membros de movimentos sociais e sindicais, associações e cooperativas do campo, entre outros (MEDEIROS, 2019). É um público diversificado, haja vista que o campo não é um contexto homogêneo, em termos sociais e identitários. Nas palavras de Arroyo (2015), há diferentes campos, com sujeitos diversos, com práticas culturais, geracionais, ambientais e políticas plurais.

2 Informações construídas com respaldo no site oficial do Curso na universidade. 
Em referência à sua proposta curricular, organiza-se a partir de 3.210 horas/aulas distribuídas em (no mínimo) oito semestres letivos de formação docente. Seu currículo oficial está sistematizado em duas habilitações (a. Ciências Humanas e Sociais, e b. Ciências da Natureza - cada habilitação com uma matriz curricular) que projetam as disciplinas, os conhecimentos e os conteúdos curriculares em três núcleos formativos: formação básica; formação integradora e formação específica.

Do ponto de vista metodológico, a graduação prevê momentos de estudos na universidade, nominados de tempo escola/universidade, e momentos de atividades nas comunidades do campo (em diferentes contextos - escolas, associações, comunidade em geral), intitulados de tempo comunidade. Essa perspectiva metodológica é entendida no Projeto Pedagógico de Curso (2013) como a Pedagogia da Alternância.

Os apontamentos levantados inicialmente nesta seção denotam a especificidade da Licenciatura Interdisciplinar em Educação do Campo da UFERSA, nos permitindo inferir ainda que tal licenciatura não se associa, na maior parte, com o que comumente encontramos no Brasil a nível de organização curricular e metodológica em relação aos cursos de formação inicial docente, dada a complexidade de promover o currículo da graduação. Tal complexidade demanda o diálogo/contato permanente da coordenação de curso com os alunos, com os professores formadores e com a universidade como um todo (alguns de seus setores e instâncias acadêmicas).

Tomando como referência esse entendimento, as reflexões sobre nossa experiência profissional na coordenação de curso da Licenciatura Interdisciplinar em Educação do Campo da UFERSA, as quais enfatizarão os desafios e as tensões na atuação profissional do coordenador de curso de graduação no período de maio do ano de 2014 a março do ano de 2016, se constituirão com base nesses três componentes essenciais no desenvolvimento das atividades na LEDOC/UFERSA. Assim, organizamos os próximos escritos com respaldo no trabalho desenvolvido pela coordenação de curso da LEDOC/UFERSA em diálogo/ interação com os estudantes, os professores formadores da graduação e a universidade.

\section{A COORDENAÇÃo de CURSO E OS ESTUdANTES da GRADUAÇÃo}

Quando pensamos em dar ênfase ao trabalho promovido pela coordenação de curso na LEDOC/UFERSA com os estudantes da graduação como primeiro componente para as reflexões acerca de nossa experiência profissional no período de maio de 2014 a março 2016, fizemos a partir do seguinte entendimento: a coordenação de curso tem como objetivo principal desenvolver suas ações com foco na melhoria do ensino na graduação (FERNANDES, 2012), o qual é perspectivado a um público específico, ou seja, o alunado.

Na LEDOC/UFERSA, a diversificação do alunado, composto por sujeitos com características sociais plurais, pesou para a existência de alguns desafios na atuação profissional do coordenador, os quais culminaram com o desenvolvimento de tensões de diferentes domínios. O primeiro desafio à atuação profissional na coordenação de curso da LEDOC/ UFERSA junto ao alunado diz respeito ao atendimento às demandas profissionais e pessoais dos discentes. O Curso LEDOC/UFERSA tem suas atividades formativas objetivadas em seu Projeto Pedagógico de Curso (2013) para serem desenvolvidas pelo período diurno. 
Dessa forma, para muitos alunos que residiam e/ou trabalhavam no meio rural, as atividades da graduação que se concentravam, muitas vezes, pelo dia inteiro na universidade se tornavam um limite para a continuidade dos estudos.

Frente a esse desafio, a coordenação de curso, com o apoio do colegiado da graduação, o alunado e as instâncias da universidade (em especial da Pró-Reitoria de Graduação) conseguiram concentrar as atividades de ensino pelo turno matutino, o que em parte sanou as demandas dos estudantes. Porém, a mudança intensificou a sobrecarga de atividades para a coordenação, haja vista que, como não havia condições de incluir toda a carga horária dos semestres letivos em um único turno na perspectiva de organização curricular convencional da universidade (todas as disciplinas ofertadas nos semestres de uma só vez), o curso passou a organizar suas atividades em módulos, isto é, em blocos de disciplinas.

Cada módulo era constituído, em média, de duas ou três disciplinas por vez. Ao término de cada módulo, iniciava-se outro bloco de componentes curriculares. Ao longo do semestre, cada turma do curso vivenciava três módulos de disciplinas. Essa característica na organização das atividades da graduação, com o passar do tempo, pesou e se tornou quase insustentável, uma vez que o registro de frequência das aulas no sistema integrado de gestão de atividades acadêmicas (SIGAA) da instituição (plataforma responsável pelo registro institucional das ações dos cursos de graduação), o choque de horários entre disciplinas para os alunos que não conseguiam aprovação no semestre letivo anterior e a quantidade de atividades dos professores formadores do curso que não podiam seguir a perspectiva institucional de registro de suas atividades de ensino na graduação contribuíram para o seu fim.

No entanto, os quase dois anos ${ }^{3}$ de organização das atividades na graduação, seguindo a perspectiva modular, acarretaram em tensões para a coordenação, especialmente em relação aos docentes da instituição que, muitas vezes, não aceitavam tal perspectiva. Desse modo, o embate da coordenação de curso com docentes externos à graduação em reuniões departamentais, conselhos superiores, entre outras instâncias da universidade, para aprovação de questões relativas ao curso se tornou frequente.

Para Silva (2017), não é simples, em alguns contextos, o/a entendimento/aceitação pelas instituições de educação superior brasileiras acerca da perspectiva de formação docente vivenciada nos cursos de licenciatura em educação do campo no país, principalmente no que se refere à organização curricular e metodológica com base na Pedagogia da Alternância. No caso da LEDOC/UFERSA, a organização das atividades de ensino no curso causou estranhamento em parte da instituição, haja vista que não se associava ao que se desenvolvia na maioria dos cursos de graduação da UFERSA. É plausível pontuar que, no campus de Mossoró, espaço em que se localiza a graduação, o curso em debate é a única licenciatura presencial existente (situada no conjunto de 20 cursos de bacharelado presenciais).

Dando continuidade à reflexão a respeito de nossa atuação profissional na coordenação de curso com os estudantes da graduação, salientamos o trabalho/uso com/das tecnologias de informação e comunicação na instituição pelos graduandos. Muitos discentes, especial-

3 Destacamos que, quando iniciamos nosso trabalho na coordenação de curso (maio de 2014), a perspectiva de organização das disciplinas por semestre letivo em módulos já se encontrava em exercício. Desde que o curso começou suas atividades de ensino (dezembro de 2013), houve a demanda de rever sua organização, em termos de metodologia, haja vista que não contemplava as demandas e realidades dos alunos quanto à continuidade dos estudos na graduação. 
mente os que concluíram o Ensino Médio há alguns anos, tinham dificuldades para acessar e utilizar os canais/meios de comunicação institucionais, tanto para a realização de matrícula quanto para a operacionalização das atividades de ensino no curso, de forma geral.

Esse aspecto, com o aumento do número de estudantes ingressantes na graduação (em média de 50 a 60 alunos por semestre letivo), se efetuou como um grande desafio. A quantidade de tempo destinada à orientação discente, especialmente no período de matrícula acadêmica, fez que as atividades da coordenação se destinassem, especialmente, a essa atribuição, limitando-nos de exercer outras ações de cunho curricular, pedagógico, administrativo e político. Como tensão oriunda desse contexto, relatamos o sentimento de impotência para cumprir com êxito todas as atribuições diárias registradas pela instituição à coordenação de curso.

Em verdade, quando as licenciaturas em educação do campo foram aprovadas por meio do Edital SESU/SETEC/SECADI/MEC, nº. 2, de 31 de agosto de 2012, para serem cursos regulares de graduação nas instituições, ficou subentendido que, além dos códigos de vagas ( 15 códigos para cada curso) destinados à contratação efetiva de professores para atuação nos cursos, as universidades receberiam mais dois códigos de vagas referentes à contratação efetiva de técnicos administrativos para auxiliarem exclusivamente nas atividades das licenciaturas, o que somaria ao trabalho da coordenação de curso (BRASIL, 2012; MOLINA; ANTUNES-ROCHA, 2014). Todavia, na UFERSA, essa realidade não se materializou. Em virtude da falta de profissionais para atuação nas funções técnico-administrativas da instituição, os dois códigos de vagas destinados à contratação de profissionais que auxiliariam no trabalho da coordenação de curso ficaram disponíveis, até onde sabemos, à instância departamental em que a licenciatura se encontrava alocada. Assim, os funcionários contratados pela instituição contribuiriam nas atividades da coordenação, porém, não de forma exclusiva.

Ainda como desafio na atuação profissional da coordenação de curso com os estudantes da graduação, no período de maio de 2014 a março de 2016, registramos a implementação da assistência estudantil aos licenciandos. Similarmente ao que se prescreveu no Edital SESU/SETEC/SECADI/MEC, $\mathrm{n}^{\circ} .2$, de 31 de agosto de 2012, quanto à disponibilidade de códigos de vagas para a contratação efetiva de professores e técnico-administrativos para o trabalho nos cursos, cada licenciatura receberia um valor financeiro específico (oriundo do Ministério da Educação) distribuído para o desenvolvimento das atividades na graduação pelo período de três anos. Esse valor financeiro poderia ser organizado para o custeio das atividades de ensino com os alunos e demandas internas ao curso, inclusive os serviços de alimentação, xerografia, transporte, entre outros; porém, não poderia ser convertido em bolsas de auxílio de qualquer natureza.

Com esse contexto, os alunos da licenciatura ficaram limitados em participar de alguns programas de assistência estudantil da instituição, uma vez que se tinha o entendimento, por parte de instâncias administrativas superiores da UFERSA, de que o valor financeiro destinado ao curso supriria as demandas do alunado e do curso. No entanto, nem sempre a manutenção dos recursos atendia às demandas diárias estudantis. Como exemplo, citamos os atrasos nos processos licitatórios abertos pela instituição para a contratação de serviços e o repasse anual dos recursos pelo Ministério da Educação. 
Esse quadro contextual promoveu tensões no que diz respeito à relação da coordenação tanto com alguns estudantes da graduação, que nem sempre entendiam essas questões e, na maioria das vezes, também não tinham condições socioeconômicas para arcar com as despesas que a universidade exigia com as ações de ensino em seu dia a dia, quanto com os setores administrativos e de planejamento da instituição. Estes com muita frequência, solicitavam informações acerca das atividades a serem desenvolvidas pelo curso em cada semestre letivo e do alunado, as quais nem sempre eram possíveis de organizar de imediato, já que exigiam o desenvolvimento de inúmeros levantamentos documentais com os alunos, com os professores formadores, entre outros sujeitos e instâncias acadêmicas da instituição.

Como conclusão desse primeiro componente da reflexão que desenvolvemos quanto à atuação profissional na coordenação de curso da LEDOC/UFERSA junto ao alunado da graduação, pontuamos que, em razão do tempo, nem todos os desafios e tensões foram possíveis de registrar. Entretanto, salientamos que os desafios e as tensões relatadas aqui foram, com base em nossas experiências profissionais, os principais, nos exigindo compromisso, fôlego e colaboração com sujeitos e instâncias da universidade para, em parte, saná-los.

\title{
A COORDENAÇÃo DE CURSO E OS PROFESSORES FORMADORES
}

Silva (2017), em sua tese de doutoramento sobre a formação de professores na Licenciatura em Educação do Campo do Instituto Federal de Educação, Ciência e Tecnologia do Pará - IFPA, relata, a partir de sua experiência na coordenação de curso, que um dos desafios vividos por ela condiz ao não entendimento por parte de alguns professores formadores da licenciatura acerca do que seja a Educação do Campo e sua relação com a proposta de formação docente materializada no curso. O desafio registrado no estudo doutoral da autora também compôs nossa atuação profissional na LEDOC/UFERSA. Para Caldart (2012, p. 259):

\begin{abstract}
A Educação do Campo nomeia um fenômeno da realidade brasileira atual, protagonizado pelos trabalhadores do campo e suas organizações, que visa incidir sobre a política de educação desde os interesses sociais das comunidades camponesas. Objetivo e sujeitos a remetem às questões do trabalho, da cultura, do conhecimento e das lutas sociais dos camponeses e ao embate (de classe) entre projetos de campo e entre lógicas de agricultura que têm implicações no projeto de país e de sociedade e nas concepções de política pública, de educação e de formação humana.
\end{abstract}

Complementando os escritos de Caldart (2012), destacamos que a Educação do Campo, enquanto movimento nacional de educação, é recente. Seu surgimento data do final da última década do século XX e início do século XXI (MUNARIM, 2008; SANTOS, 2017). Os cursos de licenciatura em educação do campo, sendo parte constituinte desse movimento educacional, também se apresentam como uma nova modalidade de graduação no Brasil (MOLINA, 2017; MEDEIROS, 2019). Destarte, entendemos que alguns professores formadores, após serem efetivados, desconheciam a LEDOC/UFERSA e a Educação do Campo, necessitando de tempo para se inserir na perspectiva formativa no curso e se engajar nas ações da formação docente. Como tensão, reflexo dessa realidade, pontuamos as 
dificuldades para apoio aos professores formadores em suas demandas na graduação, uma vez que nosso tempo e nossas ações na coordenação de curso eram múltiplos.

As atividades da coordenação de curso, especialmente no ano de 2014, eram intensas. A LEDOC/UFERSA se inseria na instituição e cotidianamente muitas atribuições emergiam. Registramos que, tal como o Curso LEDOC, a própria instituição teve seu surgimento recente, no ano de 2005. Sua expansão local fez parte do Programa de Apoio aos Planos de Reestruturação e Expansão das Universidades Federais - REUNI. Esse fator também pesou em nossas atividades diárias, haja vista que, em nossa interpretação, muitas questões relativas ao desenvolvimento acadêmico ainda se encontravam em aberto e em construção.

No que concerne ao próximo desafio referente à atuação profissional na coordenação de curso com os professores formadores, no período de maio de 2014 a março de 2016, aludimos o trabalho coletivo com um corpo docente multidisciplinar. É sabido na literatura acadêmica que a formação inicial dos professores da Educação Superior é fundamental para o início de sua construção identitária profissional. Infelizmente, por não existir no país a obrigatoriedade de cursos para a qualificação profissional para o ingresso no magistério superior, é na formação inicial em diferentes áreas do conhecimento que construímos as primeiras representações acerca da docência no ensino universitário, uma vez que é o nosso primeiro contato com essa etapa educacional (ZABALZA, 2004; GARCIA; DOMINGUÉZ, 2011; SEVERINO, 2013).

Pelo fato de o corpo docente da LEDOC/UFERSA ser constituído por profissionais com formação inicial (e também stricto sensu) em diferentes âmbitos do conhecimento, as representações acerca da Educação, da formação docente, do ensino de graduação, entre outras, nem sempre confluíam no coletivo, gerando tensões interpessoais em reuniões do colegiado e em decisões a serem tomadas conjuntamente. O "diferente", em muitos momentos, foi motivo para estranhamento.

Ao término deste segundo componente reflexivo de nossa experiência na coordenação de curso da LEDOC/UFERSA, ressaltamos que, mesmo em meio às diferenças, conseguimos, gradativamente, avançar enquanto coletivo docente que, aos poucos, lutou para a consolidação da graduação na universidade e, por conseguinte, para o reconhecimento da licenciatura junto ao Ministério da Educação. Não vivenciamos caminhos fáceis, porém, houve esforço por parte de alguns docentes para que o diálogo não se tornasse verticalizado e as ações seguissem tendo como referência prioritária o caráter democrático e participativo.

\section{A COORDENAÇÃo dE CURSO E A UNIVERSIDADE}

Destacamos que a coordenação de curso é uma instância representativa da universidade. Ela é parte e se constitui como instância universitária (FERNANDES, 2012). Desse modo, exercer a função de coordenador de curso nos trouxe a responsabilidade, o tempo todo, de representá-la e de zelar para que as decisões regimentais e estatuárias da instituição fossem, em rigor, efetivadas em nossas ações.

Por sua vez, exercer a função de coordenador de curso na Licenciatura Interdisciplinar em Educação do Campo nos trouxe também a responsabilidade de lutar com a Educação do Campo e nos inserirmos (como já o fizemos em relação à função exercida na coordenação) 
no Movimento de Educação do Campo no País. Dessa forma, um desafio experienciado na atuação profissional na coordenação de curso junto à universidade concerne à mediação dos interesses e objetivos de ambas as instâncias (universidade e Educação do Camporepresentada pelos estudantes).

Nem sempre as condições existenciais do alunado da LEDOC/UFERSA (público que caracteriza a Educação do Campo, a nível de representação social e cultural) estiveram alinhadas às prescrições normativas da instituição. Mediar os objetivos e as intenções de ambos (universidade e estudantes) que, muitas vezes, eram antagônicos, não foi tarefa fácil. Como consequência desse desafio, tivemos com frequência o nosso desgaste físico, mental e psíquico, limitando-nos de exercer e desenvolver outras atividades para além da coordenação (citamos a pesquisa e, principalmente, as ações de extensão). Nos percebíamos, continuamente, entre disputas que atestavam, além de objetivos e interesses, muitas vezes, diferentes relações de poder e dominação estabelecidas e estandardizadas na sociedade e, particularmente, na cultura organizacional universitária brasileira. Mesmo em meio ao cenário vivenciado, sempre primamos na coordenação de curso pela formação docente atenta e sensível à Educação do Campo, situada no semiárido potiguar.

Também registramos que a ausência de experiências da universidade com a formação inicial de professores da Educação Básica se referenciou como um desafio à coordenação. A inexistência de fóruns de licenciatura e/ou outras instâncias com professores da área de Educação (com formação inicial e continuada) dificultou nossas ações. Os poucos setores da instituição (quase sempre vinculados à Pró-Reitoria de Graduação) que se incumbiam de questões relativas à formação docente, como o Comitê Gestor Institucional de Formação Inicial e Continuada de Profissionais do Magistério da Educação Básica (COMFOR), do qual fizemos parte, realizavam reuniões esporádicas, quase sempre para discutir aspectos burocráticos concentrados de demandas do Ministério da Educação. O isolamento da coordenação de curso, dada a realidade, foi uma consequência desse contexto.

Frisamos que, nesse mesmo período (maio de 2014 a março de 2016), conseguimos, no Curso LEDOC/UFERSA, instituir o Núcleo Docente Estruturante e o Conselho de Curso, instâncias que contribuíram junto ao trabalho da coordenação, principalmente nas demandas que exigiam a representação do corpo docente e do alunado.

Finalmente, como síntese de nossas considerações acerca do registro teórico-experiencial construído no decurso deste texto, apresentamos alguns apontamentos a respeito de nossa atuação profissional na coordenação de curso de graduação que, pensamos, podem acrescentar às produções acadêmicas que se reportem ao tema como objeto investigativo. Assim, registramos:

- a atuação profissional do docente universitário na coordenação de curso de graduação está limitada à cultura organizacional da instituição e às relações de poder existentes em cada contexto;

- o trabalho coletivo na coordenação de curso de graduação é fundamental, porém, é necessário que ele esteja institucionalizado (por meio de conselhos, colegiados, entre outras instâncias);

- tal como acreditamos ser necessária a formação inicial e continuada específica para o exercício da docência na Educação Superior, vemos que é essencial a for- 
mação profissional para a atuação na coordenação de curso de graduação, especialmente na área da gestão universitária;

- é indispensável o apoio/suporte técnico-administrativo, bem como dos departamentos e dos centros acadêmicos para o desenvolvimento das ações da coordenação de curso. A ausência desse apoio/suporte sobrecarrega o coordenador e dificulta sua atuação profissional.

Por fim, alertamos, mais uma vez, para a necessidade de pesquisas que atentem ao difícil trabalho da coordenação de curso de graduação na Educação Superior. Com esse registro, acreditamos que somaremos, porém, há inúmeras realidades que necessitam ser conhecidas e analisadas. Ainda assinalamos que são plausíveis novos estudos acerca da gestão universitária como um todo. Se o exercício da coordenação de curso de graduação não é algo simples, entendemos que a atuação profissional em pró-reitorias, diretorias de centros acadêmicos e faculdades, chefias de departamentos, entre outros, também não são. É preciso, no contexto científico, avançar e aprofundar o debate e os conhecimentos sobre esses temas.

\section{CONSIDERAÇões FINAIS}

Este texto configurou-se como um registro teórico-experiencial que destacou reflexões sobre desafios e tensões na atuação profissional do professor universitário na coordenação de curso de graduação na Educação Superior. Para tanto, tomou como referência central a literatura, nacional e internacional, acerca da docência universitária, bem como a nossa experiência vivida na coordenação do Curso de Licenciatura Interdisciplinar em Educação do Campo da UFERSA, no período de maio de 2014 a março de 2016. Por tudo o que discutimos nas seções anteriores, registramos alguns aspectos conclusivos, na intenção de complementar os escritos desenvolvidos e reforçá-los.

Em primeiro lugar, a coordenação de curso de graduação, sendo uma instância representativa do trabalho desenvolvido pelas instituições de educação superior brasileiras, deve, em nossa interpretação, promover ações profissionais que objetivem sempre a qualificação/melhoria do ensino. Afinal, seu foco é o desenvolvimento das ações de ensino, visando à formação profissional e humana do alunado.

Para atingir seus objetivos, é essencial que estejam entendíveis, a nível documental e normativo nas instituições, quais são suas atribuições profissionais. Também registramos, tal como feito no texto, que a formação profissional para o exercício da coordenação de curso é indispensável, especialmente na área de gestão universitária. Se, para o exercício da docência na Educação Superior, enfatizou-se na história a importância dos conhecimentos disciplinares (o que acreditamos não ser suficiente, haja vista a complexidade da docência no âmbito universitário. É preciso formação inicial e continuada específica para a docência na Educação Superior), para a atuação profissional na coordenação de curso de graduação também são necessários conhecimentos e saberes da gestão educacional. Nenhum profissional exerce uma boa prática profissional sem conhecimentos e saberes para fazê-la.

Em linhas conclusivas, frisamos, novamente, que o trabalho na coordenação de curso de graduação não pode ser pensado apartado da cultura organizacional das instituições 
e das relações de poder que delas fazem parte. Ainda, alertamos para a necessidade de apoio/suporte técnico-administrativo, dos departamentos, dos centros acadêmicos, entre outros. Sem esse apoio/suporte, há uma sobrecarga de tarefas ao coordenador, o que precariza sua atuação profissional e mina suas condições de desenvolver ações mais eficazes no curso de graduação.

\section{REFERÊNCIAS}

ANASTASIOU, Lea das Graças Camargo. A função pedagógica da coordenação de curso de graduação. In: ISAIA, Silvia Maria de Aguiar; BOLZAN, Doris Pires Vargas (Org.). Pedagogia universitária e desenvolvimento profissional docente. Porto Alegre: EDIPUCRS, 2009, p. 45-62.

ARROYO, Miguel. Os Movimentos Sociais e a construção de outros currículos. Educar em Revista, v. 31, n. 55, p. 47-68, fev. 2015.

BARROS, Conceição de Maria Pinheiro; DIAS, Ana Maria Iorio. A formação pedagógica de docentes bacharéis na Educação Superior: construindo o Estado da Questão. Revista Educação em Questão, Natal, v. 54, n. 40, p. 42-74, jan./abr. 2016.

BONDÍA, Jorge Larrosa. Notas sobre a experiência e o saber de experiência. Rev. Bras. Educ., n. 19, p. 20-28, 2002.

BRASIL. Lei $\mathbf{n}^{0}$. 5.540, de 28 de novembro de 1968. Disponível em: <http://www.planalto.gov.br/ccivil_03/leis/L5540.htm>. Acesso em: 4 abr. 2020.

. Lei de Diretrizes e Bases da Educação Nacional. Lei nº. 9.394, 20 de dezembro de 1996. Disponível em: <http://www.planalto.gov.br/ccivil_03/LEIS/L9394.htm>. Acesso em: 4 abr. 2020.

. Lei $\mathbf{n}^{0}$. 10.861, de 14 de abril de 2004. Disponível em: $<$ http://www.planalto.gov. br/ccivil_03/_Ato2004-2006/2004/Lei/L10.861.htm>. Acesso em: 4 abr. 2020.

. Secretaria de Ensino Superior (SESu). Secretaria de Educação Profissional e Tecnológica (Setec). Secretaria de Educação Continuada, Alfabetização, Diversidade e Inclusão (Secadi). Edital $\mathbf{n}^{0} .2$, de 31 de agosto de 2012. Chamada Pública para seleção de Instituições Federais de Educação Superior - IFES e de Institutos Federais de Educação, Ciência e Tecnologia - IFET, para criação de cursos de Licenciatura em Educação do Campo, na modalidade presencial. Brasília, 2012.

CALDART, Roseli Salete. Educação do Campo. In: CALDART, Roseli Salete; PEREIRA, Isabel; ALENTEJANO, Paulo; FRIGOTTO, Gaudêncio (Org.). Dicionário da Educação do Campo. São Paulo-SP: Expressão Popular, 2012, p. 257-264. 
CUNHA, Maria Isabel da. Inovações na Educação Superior: impactos na prática pedagógica e nos saberes da docência. Em Aberto, v. 29, n. 97, p. 87-102, set./dez. 2016.

FERNANDES, Rosana César de Arruda. Coordenação de Curso de Graduação: das políticas públicas à gestão institucional, 248s. Tese (Doutorado em Educação). Universidade de Brasília, Brasília, 2012.

FERREIRA, Valéria Silva. As Especificidades da Docência no Ensino Superior. Revista Diálogo Educacional, Curitiba, v. 10, n. 29, p. 85-99, jan./abr. 2010.

FRANCO, Maria Amélia Santoro. Relações do docente-bacharel do ensino superior com o saber didático-pedagógico: dissonâncias e rupturas entre saberes e práticas. Em Aberto, v. 29, n. 97, p. 61-72, set./dez. 2016.

GARCIA, Marcelo; DOMÍNGUEZ, Carmen Yot. Los profesores como diseñadores: nuevas tareas para los docentes universitários. Educação, Santa Maria, v. 36, n. 3, p. 365-386, set./dez. 2011.

MARCON, Silvana Regina Ampessan. Comportamentos que constituem o trabalho de um gestor de curso de graduação, 247s. Tese (Doutorado em Psicologia). Universidade Federal de Santa Catarina, Florianópolis, 2008.

. Atribuições dos cargos de coordenação e subcoordenação de cursos de graduação. In: Colóquio Internacional sobre Gestão Universitária na América do Sul, 4, 2011, Florianópolis/SC, Anais... Florianópolis, 2011.

MASETTO, Marcos Tarciso. Desafios para a Docência Universitária na Contemporaneidade: professor e aluno em inter-ação adulta. São Paulo: Editora Avercamp, 2015.

MEDEIROS, Emerson Augusto de. Formação Interdisciplinar de Professores: estudo pedagógico-curricular sobre a Licenciatura em Educação do Campo da Universidade Federal Rural do Semi-Árido, 661s. Tese (Doutorado em Educação). Universidade Estadual do Ceará, Fortaleza, 2019.

MOLINA, Mônica Castagna. Contribuições das Licenciaturas em Educação do Campo para as Políticas de Formação de Educadores. Educação \& Sociedade, Campinas, v. 38, n. 140, p.587-609, jul./set. 2017.

MOLINA, Mônica Castagna; ANTUNES-ROCHA, Maria Isabel. Educação do Campo: História, Práticas e Desafios no âmbito das Políticas de Formação de Educadores - Reflexões sobre o PRONERA e o PROCAMPO. Reflexão \& Ação, Santa Cruz do Sul, v. 22, n. 2, p. 220-253, jun./dez. 2014. 
MOLINA, Mônica Castagna; ANTUNES-ROCHA, Maria Isabel; MARTINS, Maria de Fátima Almeida. A produção do conhecimento na Licenciatura em Educação do Campo: desafios e possibilidades para o fortalecimento da educação do campo. Rev. Bras. Educ., v. 24 , p. 1-30, 2019.

MUNARIM, Antonio. Trajetória do Movimento Nacional de Educação do Campo no Brasil. Educação, Santa Maria, v. 33, n. 1, p. 57-72, jan./abr. 2008.

SANTOS, Francisco Kennedy Silva dos. Bibliografia comentada sobre docência universitária. Em Aberto, v. 29, n. 97, p. 159-172, set./dez. 2016.

SANTOS, Ramofly Bicalho dos. História da Educação do Campo no Brasil: o protagonismo dos Movimentos Sociais. Teias, Rio de Janeiro, v. 18, p. 210-224, 2017.

SEVERINO, Antonio Joaquim. Da Docência no Ensino Superior: condições e exigências. Comunicações, Piracicaba, v. 20, n. 1, p. 43-52. jan./jun. 2013.

SILVA, Márcia Cristina Lopes e. Caminhos da interdisciplinaridade: da formação por área de conhecimento à prática educativa de egressos da Licenciatura em Educação do Campo PROCAMPO/IFPA/Campus de Castanhal, PA, 317s. Tese (Doutorado em Educação). Universidade Federal do Ceará, Fortaleza, 2017.

TARDIF, Maurice; Entrevista. Em Aberto, v. 29, n. 97, p. 133-140, set./dez. 2016.

UNIVERSIDADE FEDERAL RURAL DO SEMI-ÁRIDO. Projeto Pedagógico do Curso de Licenciatura em Educação do Campo. Mossoró-RN, 2013 (Documento Digitalizado).

VEIGA, Ilma Passos Alencastro. Formação de Professores para a Educação Superior e a Diversidade da Docência. Revista Diálogo Educacional, Curitiba, v. 14, n. 42, p. 327-342, mai./ago. 2014.

VIANA, Cleide Maria Quevedo Quixadá; MACHADO, Liliane Campos. Desenvolvimento profissional docente e intensificação do trabalho: viver ou sobreviver? Em Aberto, v. 29, n. 97 , p. 47-60, set./dez. 2016.

WAGNER, Flávia; CUNHA, Maria Isabel da. Qual a importância de inovar no ensino superior? Em Aberto, Brasília, v. 32, n. 106, p. 19-23, set./dez. 2019.

ZABALZA, Miguel. O Ensino Universitário: seu cenário e seus protagonistas. Porto Alegre: Artmed, 2004.

ZUIN, Antonio Álvaro Soares; BIANCHETTI, Lucídio. O Produtivismo na era do "publique, apareça ou pereça": um equilíbrio difícil e necessário. Cadernos de Pesquisa, v. 45, n. 158 , p. 726-750, out./dez. 2015. 


\section{DADOS DO AUTOR:}

\section{Emerson Augusto de Medeiros}

Doutorado em Educação pela Universidade Estadual do Ceará. Ceará-Brasil. Professor do Programa de Pós-Graduação em Ensino da Universidade Federal Rural do Semi-Árido. Mossoró/RN, Brasil. emerson.medeiros@ufersa.edu.br

Submetido em: 7-4-2020

Aceito em: 20-9-2020 